\title{
Fast incremental mining of web sequential patterns with PLWAP tree
}

\author{
C. I. Ezeife • Yi Liu
}

Published online: 13 August 2009

Springer Science+Business Media, LLC 2009

\section{Erratum to: Data Min Knowl Disc DOI 10.1007/s10618-009-0133-6}

The authors regret for an error that occurred in Fig. 7 of the article. The correct version of the figure is given below.

The online version of the original article can be found under doi:10.1007/s10618-009-0133-6.

\section{I. Ezeife $(\varangle) \cdot$ Y. Liu}

School of Computer Science, University of Windsor, Windsor, ON N9B 3P4, Canada e-mail: cezeife@uwindsor.ca

URL: http://www.cs.uwindsor.ca/ cezeife

Y. Liu

e-mail: woddlab@uwindsor.ca 
(a) Expt 1:Execution Times at Different Supports

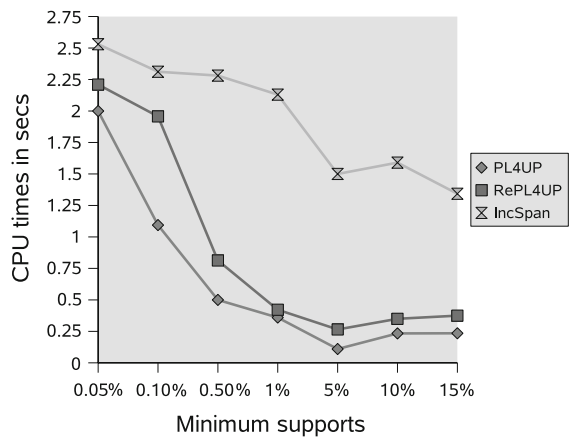

(c) Expt 3:Different Incremental dbs, $\mathrm{U}=200 \mathrm{~K}, \mathrm{~s}=1 \%$

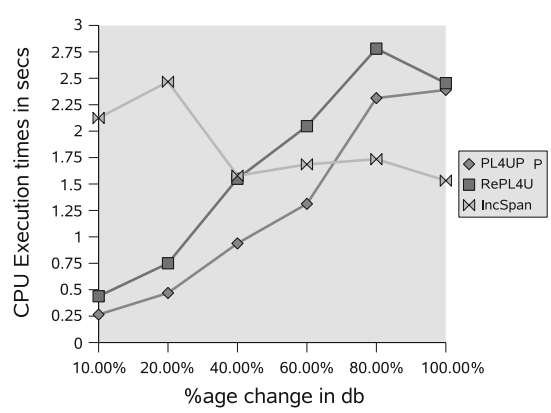

(e) Expt 5:\%age changes in $\mathrm{db}, \mathrm{U}=2.5 \mathrm{M}, \mathrm{s}=1 \%$

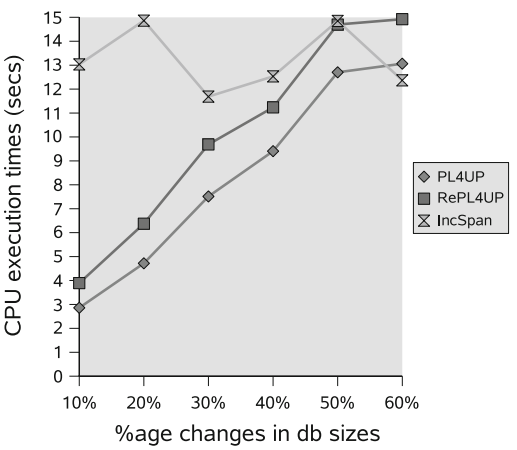

(b) Expt 2: Updated DB's,Support $1 \%, \mathrm{db}=10 \%$ of $\mathrm{U}$

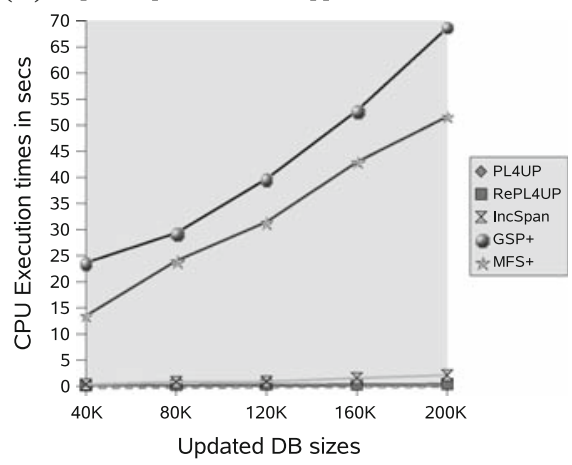

(d) Expt 4:Lower \%age db change, $\mathrm{U}=200 \mathrm{~K}, \mathrm{~s}=1 \%$

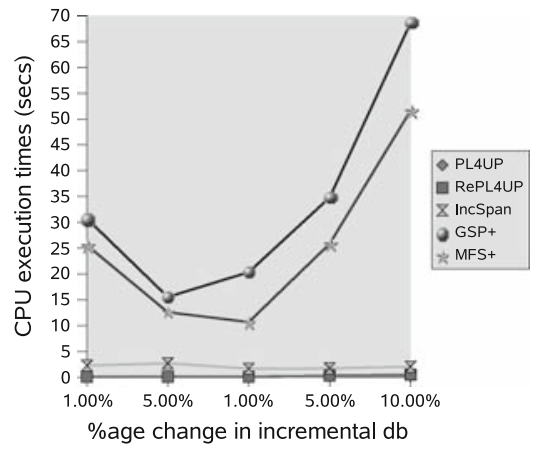

(f) Expt 8:Times for many small items, $\mathrm{U}=200 \mathrm{~K}$,

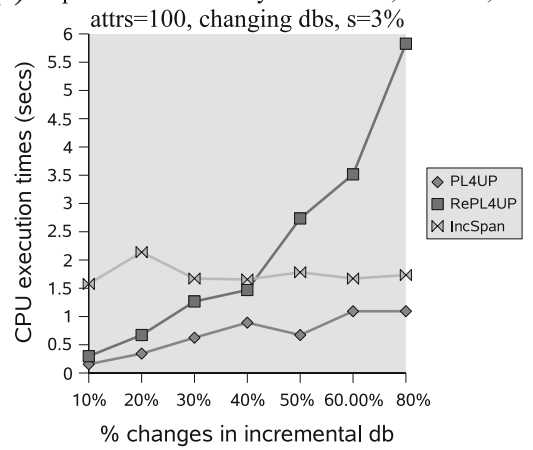

Fig. 7 Execution times trend with different supports/updated database sizes 